tions, the force of the wind may become as great as that impressed upon the structure by the action of gravity. The recent account, in this paper, of the proposed new Forth Bridge, was a good example of the provision made for wind pressure, not only on the completed structure, but also during its construction. Notwitbstandirg this, the report of the recent Commission on Wind Pressure substantiates the statements already alluded to. This distribution of wind pressure over any surface appears to be very little understood, though the matter is being carefully investigated by more than one experimenter, and some results have recently been published. It seems, however, hardly credible that the maximum pressure to which a structure may be exposed is almost as great a matter of uncertainty ; yet such is the case. The papers on wind pressure, above referred to, in spite of the existence of so many anemometers, endeavour to ascertain from a variety of sources, such as previous accidents, and reports of the effect of wind in storms, what the probable maximum pressure has been, both, however, assuming values for purposes of calculation far less than are actually reported. In the same manner, the Commission decided upon a limiting value only a little more than 62 per cent. of a pressure recorded by an anemometer, and believed by them to have actually taken effect in this country.

The fact is, that the motion of the air is, beyond all expression, most complicated. Were it not for this, there would be no necessity for obtaining both the velocity and pressure of the wind, for there is, by a first principle of dynamics, a fixed relation between these two elements; and if one were known, the other could be, at any rate, approximately deduced. In reality, any attempt to treat the wind as having steady motion for more than a very small distance in space, is certain to involve serious error, and the complications which are introduced, from even slight disturbing causes, seen quite beyond the powers of investigaition. The engineer is concerned both with prejudicial effect of the wind upon structures, and its useful effect upon wind-motors. In both these cases the conditions are such as to greatly interfere with the steady motion of the wind, and the effect due to locality must be estimated and allowed for. The meteorologist needs observations of the wind at all elevations, and as pointed out by Mr. Laughton in his address, particularly at higher ones, where, jud jing from the experience of aëronauts, the motion of the wind is nearly as complex as below. Until the motion of the wind is better understood, weather forecasts must be more or less unreliable, and what has been said with reference to the mechanical excellence of the present anemometers and the regular tabulation of results, must not lead to the idea that there is no room for improvement. On the contrary, there is yet much to be done in directions which can here be only briefly indicated.

First, there is great necessity for improvement in the lubrication of the instruments, especially of that portion recording direction, so that in viewing a weather chart of the Times it may be certain that in light winds the arrows really show the direction and not directly the opposite one. Such an error as this, perhaps from some distant station, causes whole columns of the bulky hourly records to be worse than useless.

Secondly, the reductions for the relative velocity of the wind and cups, if made at all, ought not to be made, as is at present the case, by a factor now well known as the result of much costly investigation, to be erroneous.

Lastly, the locality of anemometers should be more carefully selected, or at least taken more closely into account, in discussing the effect of wind in storms.

The importance of some reform in the matter of wind measurement is obvious, since it is only by continued observations, under improved conditions, that a more reliable and satisfactory knowledge can be obtained of the aërial ocean in which we live.
THE ZOOLOGICAL SOCIETY AND "ZUUMBO"

$A^{\mathrm{T}}$ the General Meeting of the Fellows of the Zoological Society on Thursday last, Prof. Flower made the following remarks with reference to the subject of the elephant, "Jumbo" :-

Before the Meeting separates I wish to make a few observations upon the subjects which have just been under discussion. It has been said that there should be power in the Bye-laws to call Special Meetings of the Fellows of the Society; and the subject is certainly deserving of the consideration of the Council. The probable explanation why there is no such power already, lies in the fact that there are regular Monthly General Meetings at which all Fellows are able to be present, to ask any questions or to make any observations they think fit upon the managament of the affairs of the Society and, upon notice having been given, to propose any resolutions.

With reference to the action of the Council in the particular case under consideration, their legal powers to part with any of the animals under their care have now been fully affirmed by Mr. Justice Chitty's judgment, and the expediency of their being able to exercise these powers at their discretion in all ordinary cases does not seem to be doubted by any sensible person. It has, however, been asserted that there was something exceptional in the case of the elephant in question. I would ask when, and by what means, can the line be drawn between an ordinary and exceptional animal? Two elephants have been sold within my recollection (one in 1854 , the other in 1873 ), and no one ever disputed the power or discretion of the Council in parting with either. Certainly neither of them was called "Jumbo," a name which has clearly done much to foster the present agitation. If our "Jumbo" had been called by some name as unpronounceable as that of the two Indian elephants now in the Society's possession we should have heard much less of his virtues.

To: speak of this animal as is done by Sir George Bowyer in the Times of to-day, as in any way comparable to the Codex Alexandrinus, is only equalled in absurdity by the statement lately made in a letter to the same paper by another Fellow of the Society, that if a certain Chancery suit were successful the animal would remain as a "permanent" inhabitant of the Gardens. How immortality was to be conferred on "Jumbo" I do not know. Our animals are only temporary possessions. All experience tells us that even elephants die, and, moreover, that whatever may be the case in their native land (a subject on which strangely exaggerated notions prevail), in this country they are never long-lived animals. Whatever means were tried to preserve "Jumbo," whether lawsuits, chains, or stone walls, it is absolutely certain that a few years would have seen his end in one way or another.

Then as to "Jumbo" being "unique," as is constantly said, I am not quite certain what is meant by this, as there are many African elephants at present in Europe, and one other in our own Gardens. As an elephant he is by no means perfect, wanting the most characteristic ornament of his race-the tusks. He is certainly large, but probably not larger than many other male elephants of his species would grow, if kept for a sufficient length of time. This very size, however, while in one sense adding to his value, is in another a serious detriment. It was, in fact, the principal cause of the desire to part with him. Then it is said that he was exceptional on account of his great money-value; but of what that value was no one could form any idea: in the general market it was literally nothing. I doubt whether, at all events a month ago, any one but the actual purchasers would have taken him off our hands at any price. I know, for my own part, so great has been my anxiety about him for several years past-so sure did I feel that he would one day or other bring us into trouble (although I can 
scarcely say that 1 anticipated it in its present form), that I would willingly have consented to giving him away gratis if an opportunity had offered. Probably few of us admired the animal more than I did; but I have considerable knowledge of those who have attempted to keep such elephants in captivity in Europe. It is said that, as we have no difficulty in keeping lions, which are more dangerous, there need be no danger with elephants; but the deduction is not sound. A lion is always dangerous, and can be treated accordingly; an elephant, which inspires confidence by its usual docility, is on that very account a far more difficult and dangerous animal to deal with. In many zoological gardens on the Continent I have seen elephants boxed and chained up, without being allowed to take a foot of exercise, sometimes for years together; and on inquiry I have always found that it had been necessary to restrain the animal, because at some unexpected moment it had killed or injured its keeper. In India this would only be looked upon as an ordinary incident in an elephant's life; but if such an event were to happen in our Gardens (as I must say I have felt morally certain it would do sooner or later, if Jumbo remained there), what should we have had to do with the animal? Could we have ever again let him pace about the Gardens with his precious freight of little children on his back? But much worse than even killing a single keeper might have happened if the animal had once got beyond control. We have been warned by high legal authority of our responsibilities on this subject. It is possible that we may have been too apprehensive, too caref ul, about the lives of our servants and of our visitors; we may possibly bave looked at difficulties incident to the management of our gardens, into the details of which it would be useless to detain this meeting by entering upon, in too serious a light; but this was a case in which we felt that to be on the safe side was the right course to pursue. I do not say that other bolder and more enterprising managers, who might look upon the attractions of the Gardens in a more commercial spirit, might not possibly have ta'ken. a different course; for we were quite aware that the loss of the animal might for a time be detrimental to the income of the Society. For this reason we also, as custodians of the Society's finances, thought it not right to decline to avail ourselves of the very unexpected opportunity of diminishing that loss, as far as possible, by the animal's sale. Some persons have called in question the "morality" of this transaction. How any one who has ever sold a horse, cow, sheep, or pig can do so, I cannot imagine. If the purchasers elect to take an animal, knowing all its imperfections, and the vendors are satisfied that it will pass into hands where there is every reasonable prospect of its being properly treated, what more can be required? Then we have been told that we ought to have killed the elephant. To this I decidedly demur, unless the principle is admitted that every one who has a horse, a dog, or any other animal, which has become through any circumstances inconvenient for him to keep, is bound to destroy it. This may be the doctrine of a few visionary enthusiasts, but it is not common sense, it is not humanity. If the life of an animal is of any use to it (and I see no reason why this elephant may not enjoy his life for perhaps a few years longer), there is no reason for taking it away until the time comes when it is absolutely necessary to do so. Besicles, as I mentioned before, as trustees and managers of the Society's property, we are bound to look after its finances. You surely all know that the operations of the Society cannot be carried on without means, and that every penny received by the Society is spent upon the purposes indicated in the Charter; and yet many persons (I am almost ashamed to allude to such folly and ignorance), have spoken as if the Council, or the officers of the Society, had some direct pecuniary interest in selling the elephant. This brings me, in conclusion, to the one most serious side among the many ludicrous incidents that have arisen out of this affair. This is the rash or wilful misrepresentations that have been so freely indulged in against a body of gentlemen of whose general qualifications for the offices which they hold it is not perhaps necessary for me to speak in this assembly (their names should be a sufficient guarantee of this), but of whom I may say, from my intimate knowledge, that they are constantly endeavouring, often at considerable personal sacrifice, to bring their varied knowledge and experience to bear upon carrying out the work of the Society for the advancement of science, and for the benefit of the Fellows of the Society and the public generally. Our accomplished Secretary of whose successful general administration of the Society no one who did not know its condition as I happen to do before he took office, and has not watched its growing prosperity for the last five and twenty years, can form an adequate idea, has not been spared, although in his share in this transaction he certainly bad no interest but that of the Society at heart.

There is much in this which is to me a novel and painful experience; but I am told that it is what all must expect who undertake the responsibility of any kind of work for the benefit of otbers. However this may be in political life, it might bave been hoped that among those who followed the calmer pursuits encouraged by this Society, there would not have been any found who, either openly or under cover of anonymous slander. in newspaper articles, letters, and postcards, would have imputed to us, which I regret to say has been so freely done, motives absolutely contrary to those by which we know we have been ever actuated.

\section{ON DUST-EXPLOSIONS IN COLLIERIES}

THE observations and experiments of M. Vital, in France, and of Mr. Galloway, Prof. Abel, and the late Prof. Freire Marreco, in this country, have shown, beyond all question, that we must look to the power possessed by coal-dust, and possibly even by fimely-divided incombustible inorganic matter, when suspended in air, of propagating or enlarging the area of an explosion as one of the main causes of those frightful occurrences, which now and then decimate even an entire mining community. There can be little doubt, that so far as the loss of life is concerned, dust-explosions are, as a rule, far more disastrous than mere explosions of gas. A shot is blown out, or, by some mischance, the gas in the goaf, or in some hole in the roof, is fired: the concussion of air raises a cloud of dust, among the particles of which the flame rushes with explosive violence. Fresh dust is
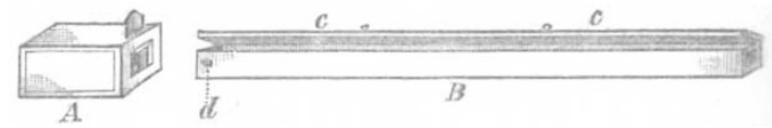

raiset, to form fresh fuel for the devouring flame, which. as in the case of the Penygraig explosion, so carefully investigated by Mr. Galloway, is thereby enabled to penetrate and search into the innermost recesses of the workings, provided they be sufficiently dry and dusty. Every particle of free oxygen is thus practically used up, and the resultant atmosphere is a suffocating mixture of nitrogen, carbonic acid, carbonic oxide, hydrocarbons, and partially-coked dust, against which the men, over whom the flame may have passed, with little hurt, have not the slightest chance.

It may possibly be of interest to those who, like myself, have to teach chemistry in a coal-mining district, to know of an experiment which illustrates in a striking manner the main features of a dust explosion. The experiment is to malse an explosion at one end of a long and narrow wooden tube, representing the gallery of a mine; to show 